\title{
The Use of Molecular Typing to Evaluate the Dissemination of Antimicrobial Resistance Among Gram-Negative Rods in Brazilian Hospitals
}

\author{
Iraci Tosin $^{1,2}$, Suzane Silbert ${ }^{1}$ and Helio S. Sader ${ }^{1}$
}

\author{
Federal University of São Paulo, Special Laboratory \\ of Clinical Microbiology ${ }^{l}$, São Paulo, SP; Federal \\ University of Santa Catarina, Centre of Biological \\ Sciences $^{2}$, Florianópolis, SC, Brazil
}

\begin{abstract}
Antimicrobial resistance has increased rapidly in Brazil and worldwide during the past few years, giving rise to a growing necessity for antimicrobial resistance surveillance programs. These programs have been instituted in order to monitor bacterial resistance in various regions, and to guide empirical antimicrobial therapy. We evaluated the use of molecular typing in multicenter surveillance programs. We also studied the dissemination modes of selected resistance profiles. Antimicrobial susceptibility to various antimicrobial agents was evaluated by the reference broth microdilution method. Bacterial isolates with selected susceptibility patterns were characterized by pulsed field-gel electrophoresis (PFGE). A total of 119 Gram-negative bacteria were molecularly typed, including 22 imipenem-resistant Pseudomonas aeruginosa, 26 ESBLproducing Escherichia coli, 27 cefoxitin-resistant-ESBL-producing Klebsiella pneumoniae, 33 Enterobacter spp., 8 Citrobacter spp., and 3 S. marcescens isolates resistant to ceftazidime. The isolates were from clinically apparent bacteremia of patients hospitalized in medical centers located in 13 cities of 11 Brazilian states. Our molecular typing results revealed a great genetic diversity among isolates of the same species. However, some major PFGE patterns were found in more than one isolate. All repeated PFGE patterns were detected in only 2 isolates, which were isolated within the same institutions or in different medical centers. We conclude that the ability to characterize organisms phenotypically and genotypically is a powerful epidemiologic tool and it provides unique information that is very important for multicenter surveillance programs.

Key Words: Molecular typing, pulsed-field gel electrophoresis, antimicrobial resistance, carbapenem-resistant Pseudomonas aeruginosa, clonal dissemination, Sentinela Program.
\end{abstract}

Antimicrobial resistance has become an important problem worldwide [1]. Bacterial resistance to antimicrobial agents has been emerging and rapidly disseminating among many nosocomial and communityacquired pathogens [2]. Control of antimicrobial resistance has become a strategic priority for hospitals

Received on 15 May 2003; revised 08 August 2003.

Address for correspondence: Dr. Suzane Silbert. Laboratório Especial de Microbiologia Clínica. Divisão de Doenças Infecciosas e Parasitárias. Universidade Federal de São Paulo. Rua Leandro Dupret, 188, São Paulo, SP, Brazil, Zip code: 04025010. Phone/Fax: (55-11) 5081-2819/5571-5180/5081-2965

E-mail: suzanesilbert@terra.com.br

The Brazilian Journal of Infectious Diseases 2003;7(6):360-369 (C) 2003 by The Brazilian Journal of Infectious Diseases and Contexto Publishing. All rights reserved. and health care providers on a global scale. As part of this effort, there are now several major programs that have been organized to conduct surveillance for antimicrobial resistance on both national and international levels [3-5].

Most surveillance programs use a conventional antimicrobial susceptibility testing method to determine phenotypic profiles. Although useful as a screening method for detecting certain resistance profiles and for selecting potentially useful therapeutic agents, conventional antimicrobial susceptibility testing methods are insensitive tools for tracing the spread of individual strains within a hospital or region. On the other hand, molecular typing methods provide powerful tools to track bacterial strains. Molecular typing contributes to the evaluation of nosocomial infection outbreaks, 
recurrent infection and clonal dissemination of specific pathogens [6,7]. Some surveillance programs have incorporated molecular typing techniques as a means of providing additional information, to detect and evaluate the mode of dissemination of multi-drug resistant (MDR) pathogens [8].

When the isolates are genotypically distinct, clustering may occur due to excessive drug pressure, which may favor resistant phenotypes within a group of unrelated isolates. On the other hand, the finding of isolates with identical or similar molecular typing in distinct patients indicates clonal dissemination. The dissemination of MDR strains between patients within medical centers has been extensively documented. In addition, reports of the dissemination of MDR bacterial clones between medical centers have recently become more common [9-11].

The Sentinela Antimicrobial Resistance Surveillance (Sentinela) Program is one of the surveillance programs in place in Brazil [12]. We characterized isolates selected from the Sentinela Program based on their susceptibility to antimicrobial agents and on their DNA macrorestriction profiles, in order to evaluate and understand the clonal dissemination of resistant strains within and among hospitals in Brazil.

\section{Materials and Methods}

Bacterial isolates. One hundred nineteen isolates were selected among 835 Gram-negative bacteria samples collected from 36 Brazilian hospitals as part of the Sentinela Program. The isolates were collected from blood stream infections from April to November of 1998. The hospitals were located in 13 cities from 11 states. Only one isolate per patient was included in the program. The isolates were identified at the participant center and they were sent to the Laboratório Especial de Microbiologia Clínica (LEMC) from the Infectious Diseases Division of the Federal University of São Paulo(UNIFESP/EPM), São Paulo, Brazil, where they were subcultured on nutrient agar slants and stored for future complementary tests.

Susceptibility testing. The antimicrobial susceptibilities of isolates to 20 compounds were evaluated by broth microdilution using MicroScan $®$ Dried Gram Negative MIC/Combo panels (Dade-Behring ${ }^{\circledR}$, Sacramento, USA), according to the National Committee for Clinical Laboratory Standards (NCCLS) instructions [13]. A standard suspension of the organisms was used to inoculate the panels, which were incubated at $35^{\circ} \mathrm{C}$ for a minimum of 16 hours. The minimum inhibitory concentration (MIC) was determined according to the lowest antimicrobial concentration showing inhibition of growth. The following antimicrobial agents were tested: cefoxitin, ceftizoxime, ceftazidime, cefotaxime, ceftriaxone, cefoperazone, cefpodoxime, cefepime, imipenem, meropenem, ampicillin/sulbactam, ciprofloxacin, aztreonam, amoxicillin/clavulanate, ticarcillin/clavulanate, mezlocillin, sparfloxacin, piperacillin/tazobactam, netilmicin, and azlocollin. Quality control measures were implemented by testing with Staphylococcus aureus ATCC 29213, Escherichia coli ATCC 25922, and Pseudomonas aeruginosa ATCC 27853, periodically during the study. The breakpoint interpretive criteria used were those established by the NCCLS [14].

Klebsiella pneumoniae and $E$. coli isolates with increased MICs $(\geq 2 \mu \mathrm{g} / \mathrm{ml})$ for ceftazidime and/or ceftriaxone and/or aztreonam were considered as possible extended-spectrum beta-lactamase (ESBL) producing strains according to NCCLS criteria [13]. The ESBL phenotype was confirmed by using the ESBL Etest strips ${ }^{\mathrm{TM}}$ (AB Biodisk, Solna, Sweden), which evaluate the variation of either ceftazidime or cefotaxime MICs when clavulanic acid is added at $2 \mu \mathrm{g} / \mathrm{ml}[15]$.

Molecular typing. The isolates were selected to be evaluated by pulsed-field gel electrophoresis (PFGE), based on their susceptibilities to selected antimicrobial agents. Thus, $P$. aeruginosa with $\mathrm{MIC} \geq 16 \mu \mathrm{g} / \mathrm{ml}$ to imipenem (22 isolates), ESBL-producing Escherichia coli (26 isolates), ESBL producing Klebsiella pneumoniae with cefoxitin MIC $\geq 16 \mu \mathrm{g} / \mathrm{ml}$ (27 isolates), and samples of Enterobacter cloacae (22 isolates), Enterobacter aerogenes (11 isolates), Citrobacter spp. (8 isolates), and Serratia marcescens (3 isolates) with $\mathrm{MIC} \geq 32 \mu \mathrm{g} / \mathrm{ml}$ to ceftazidime, which 
are probably producers of chromosomally derepressed ampC beta-lactamases, were characterized by macrorestriction analysis of chromosomal DNA using the pulsed field-gel electrophoresis (PFGE) technique [16]. Genomic DNA inserts were digested at $37^{\circ} \mathrm{C}$, during an overnight period (12 to $16 \mathrm{hs}$ ), with $10 \mathrm{U} / \mathrm{ml}$ of SpeI enzyme (New England Biolabs, Inc., Beverly, MA, USA). Electrophoresis was performed in a CHEF-DRIII apparatus (Bio-Rad, Richmond, CA, USA), under the following conditions: $0.5 \mathrm{TBE}, 1 \%$ agarose, $13^{\circ} \mathrm{C}, 200 \mathrm{~V}$. The electrophoresis ran for $21 \mathrm{hs}$, with the switch interval ramped appropriately for the species being tested [16]. Photographs of ethidium bromide-stained gels were examined visually. Isolates were considered distinct strains whenever there were 3 or more different fragments or bands in the comparisons between PFGE profiles. Isolates were considered similar (subtypes of a major PFGE pattern) whenever there were 1 to 3 band differences between PFGE patterns. Isolates with the same PFGE profile were considered indistinguishable [16]. Major PFGE patterns were identified by a capital letter, while their subtypes were denominated with the same capital letter followed by a subscribed number $\left(A_{1}\right.$ and $A_{2}$ for example).

\section{Results}

In general, molecular typing revealed considerable genetic diversity among isolates of the same species. However, some major PFGE patterns were found in more than one isolate. Isolates sharing identical or similar PFGE patterns are shown in Table 1. Repeated PFGE patterns were never detected in more than 2 isolates, which were isolated within the same institutions or from distinct medical centers.

Seventeen different PFGE patterns were observed among the 19 imipenem-resistant $P$. aeruginosa strains. Two major PFGE patterns were observed in more than one sample (two samples each) (Figure 1). Two isolates with an identical PFGE pattern (called "B") were isolated in different institutions located in the same city (São Paulo), whereas samples with similar patterns ( $\mathrm{I}_{1}$ and $\mathrm{I}_{2}$ ) were isolated from the same hospital.
Similarly, considerable genetic diversity was observed among both ESBL-producing $K$. pneumoniae and cefoxitin-resistant-ESBL-producing E. coli. Three PFGE patterns were shared by more than one $K$. pneumoniae isolate and two PFGE patterns were shared by more than one $E$. coli isolate. Each of these repeated PFGE patterns was detected in two isolates from different institutions. In addition, three of these repeated patterns were shared by isolates from institutions located in different cities.

Three PFGE patterns were shared by more than one $E$. cloacae isolate and two were shared among $E$. aerogenes isolates (Table 1). Two pairs of clonally related isolates were collected from patients hospitalized in a medical center located in São Paulo city, whereas the other repeated pattern (two samples) was found in samples isolated from different cities (São Paulo and Curitiba, Figure 2). Both pairs of $E$. aerogenes isolates sharing identical PFGE patterns were collected from patients hospitalized in cities located 700 to $1000 \mathrm{~km}$ apart (Table 1 and Figure 3). Similarly, the clonally related Citrobacter spp. strains were isolated in Juiz de Fora and São Paulo, which are located approximately $400 \mathrm{~km}$ from each other (Table 1 and Figure 4).

\section{Discussion}

The molecular typing characterization of microorganisms to provide evidence of genetic relatedness is frequently used by physicians, microbiologists, and epidemiologists as an aid in the epidemiological investigation of infectious diseases [7]. A need to determine the relatedness of organisms may arise during an outbreak investigation in which a cluster of infections due to organisms of the same species and similar antimicrobial resistance profiles is identified, in order to determine clonal spread within a microenvironment, and to determine the source of infection [6].

On the other hand, epidemiological surveillance conducted over time requires the monitoring of clonal spread, and determination of the prevalence of strains within a population to monitor the emergence and 
Table 1. Hospital location of isolates with repeated major PFGE patterns

\begin{tabular}{|c|c|c|c|}
\hline Organism & $\begin{array}{c}\text { Medical center \#/ } \\
\text { isolate \# }\end{array}$ & Location & PFGE Pattern \\
\hline \multirow[t]{4}{*}{ Pseudomonas aeruginosa } & $1 / 90069$ & São Paulo & $\mathrm{B}$ \\
\hline & $4 / 96073$ & São Paulo & $\mathrm{B}$ \\
\hline & $8 / 103073$ & Campinas & $\mathrm{I}_{1}$ \\
\hline & $8 / 103051$ & Campinas & $\mathrm{I}_{2}$ \\
\hline \multirow[t]{4}{*}{ E. coli } & $9 / 115090$ & Florianópolis & $\mathrm{G}$ \\
\hline & $16 / 115002$ & Porto Alegre & $\mathrm{G}$ \\
\hline & $14 / 102002$ & Porto Alegre & $\mathrm{L}$ \\
\hline & $15 / 102039$ & Porto Alegre & $\mathrm{L}$ \\
\hline \multirow[t]{6}{*}{ Klebsiella pneumoniae } & $2 / 101056$ & São Paulo & $\mathrm{B}$ \\
\hline & 3/111056 & São Paulo & B \\
\hline & 2/101082 & São Paulo & $\mathrm{C}$ \\
\hline & $15 / 111078$ & Porto Alegre & $\mathrm{C}$ \\
\hline & $3 / 111042$ & São Paulo & $\mathrm{F}$ \\
\hline & $10 / 121042$ & Rio de Janeiro & $\mathrm{F}$ \\
\hline \multirow[t]{6}{*}{ Enterobacter cloacae } & $7 / 97073$ & São Paulo & $\mathrm{B}$ \\
\hline & $11 / 97091$ & Curitiba & $\mathrm{B}$ \\
\hline & $1 / 97004$ & São Paulo & $\mathrm{C}$ \\
\hline & $1 / 97054$ & São Paulo & $\mathrm{C}$ \\
\hline & $1 / 97068$ & São Paulo & $\mathrm{E}$ \\
\hline & $1 / 97063$ & São Paulo & $\mathrm{E}$ \\
\hline \multirow[t]{4}{*}{ Enterobacter aerogenes } & $3 / 106061$ & São Paulo & $\mathrm{D}$ \\
\hline & $9 / 106005$ & Florianópolis & $\mathrm{D}$ \\
\hline & 8/97048 & Campinas & $\mathrm{G}$ \\
\hline & 16/97071 & Porto Alegre & $\mathrm{G}$ \\
\hline \multirow[t]{2}{*}{ Citrobacter spp. } & $5 / 95069$ & Juiz de Fora & $\mathrm{D}_{1}$ \\
\hline & $3 / 109044$ & São Paulo & $\mathrm{D}_{2}$ \\
\hline
\end{tabular}


Figure 1. Pulsed-field gel electrophoresis patterns of imipenem-resistant Pseudomonas aeruginosa isolates (lane - PFGE pattern): 1 - A; 2 - B, 3 - C, 4-D, 5-E, 6- F; 7 - B; 8 - G, 9- H, 10 - I , 11 - I , 12 - J, 13 $-\mathrm{K}, 14-\mathrm{L}, 15-\mathrm{M}, 16-\mathrm{Z}$ (control). Identical strains (PFGE type B) are shown in lanes 2 and 7, similar PFGE patterns $I_{1}$ and $I_{2}$ are shown in lanes 10 and 11, and the remaining lanes represent strains with unique PFGE patterns. $\lambda$ - lamdba marker.

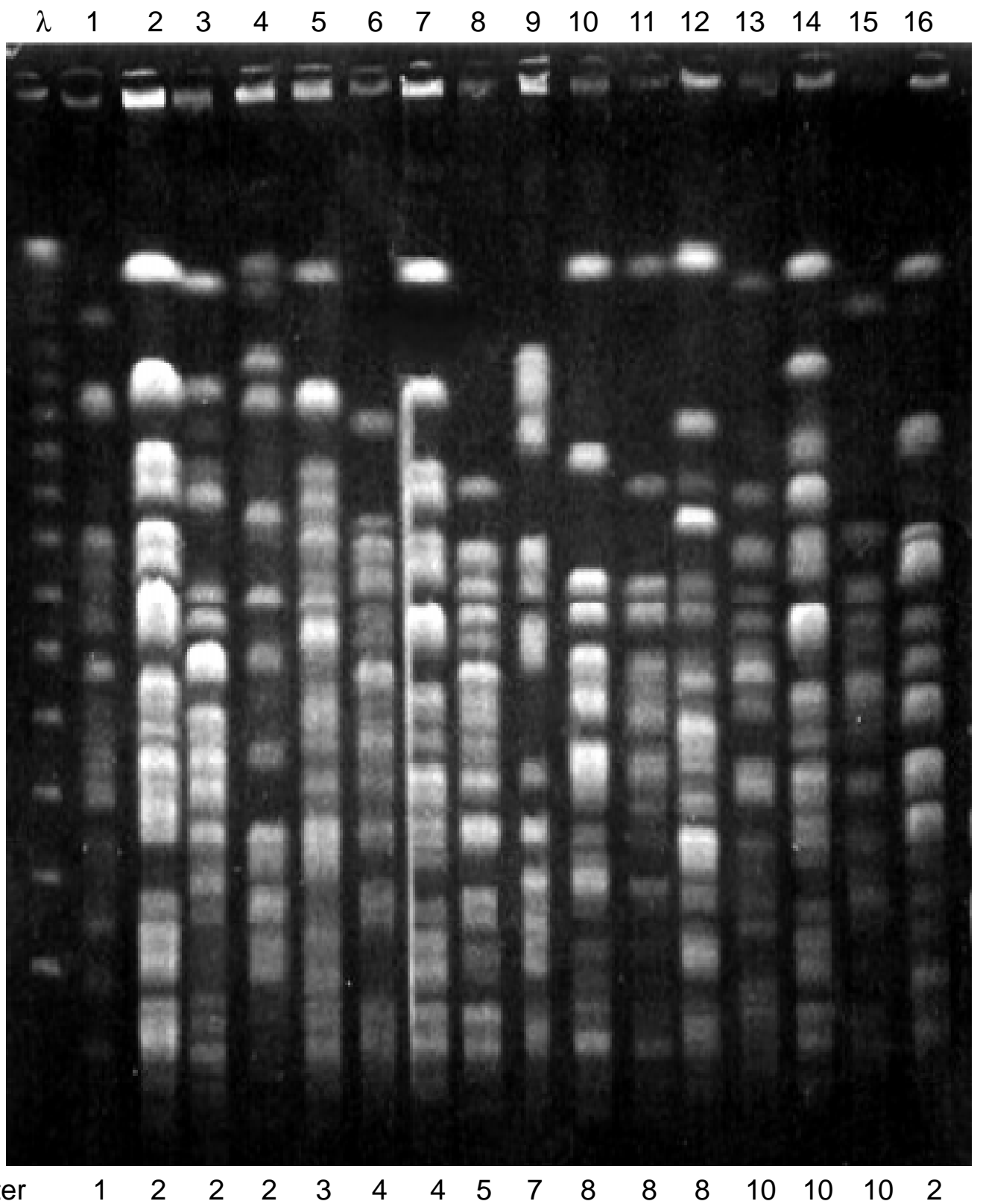

$\begin{array}{lllllllllllllllll}\text { Medical center } & 1 & 2 & 2 & 2 & 3 & 4 & 4 & 5 & 7 & 8 & 8 & 8 & 10 & 10 & 10 & 2\end{array}$ 
Figure 2. Pulsed-field gel electrophoresis patterns of Enterobacter cloacae isolates (lane - PFGE pattern): 1 $\mathrm{A} ; 2-\mathrm{B} ; 3-\mathrm{C} ; 4-\mathrm{C} ; 5-\mathrm{D} ; 6-\mathrm{E} ; 7-\mathrm{E} ; 8-\mathrm{F} ; 9-\mathrm{Z}$ (control). Identical strains are shown in lanes 3 and 4 (PFGE pattern $\mathrm{C}$ ) and in lanes 6 and 7 (PFGE pattern $\mathrm{E}$ ), respectively. The remaining lanes represent strains with unique PFGE patterns. $\lambda$ - lambda marker.

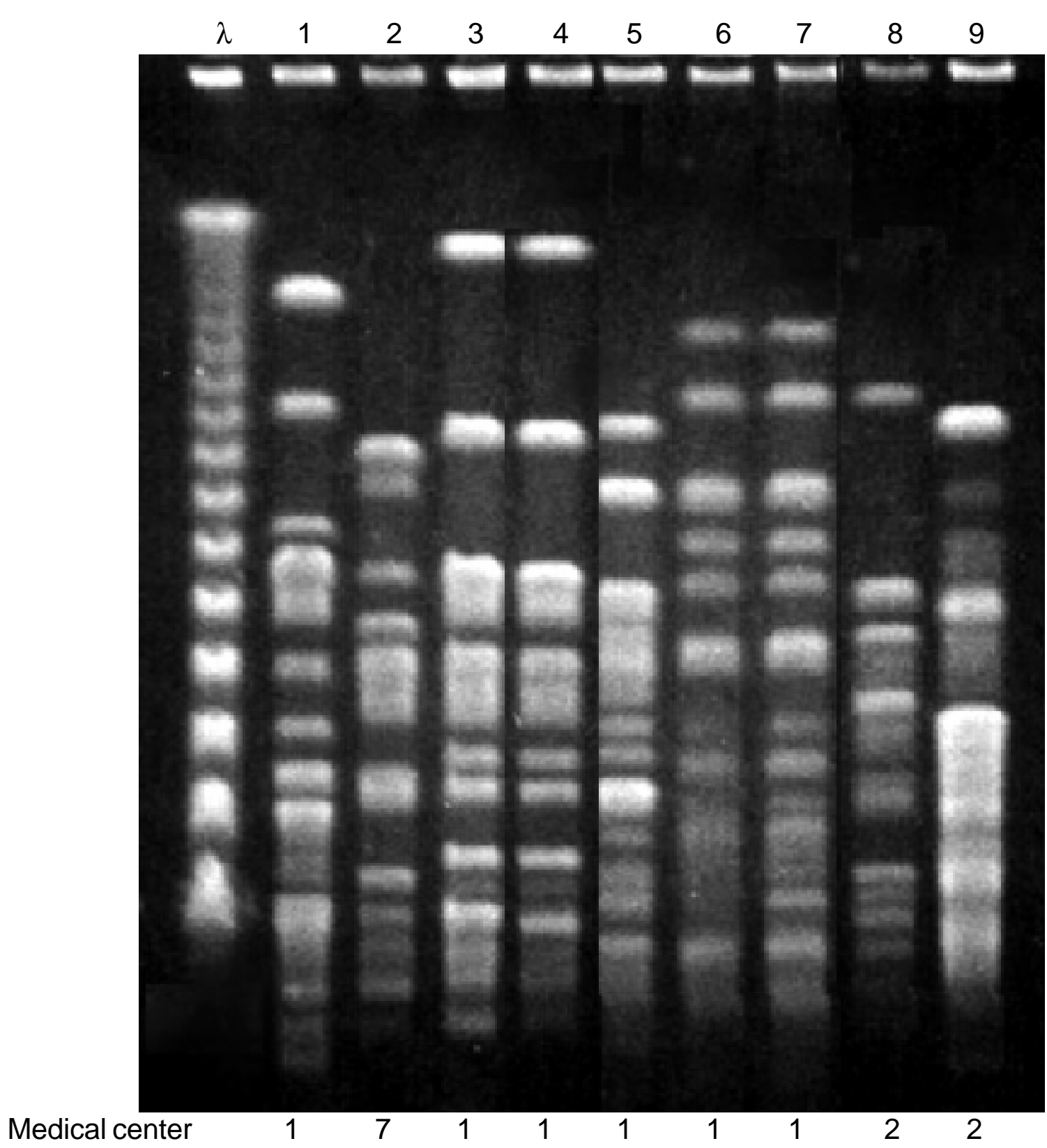


Figure 3. Pulsed-field gel electrophoresis patterns of Enterobacter aerogenes (lane-PFGE patterns): 1 - A;2 - B; 3-C; 4-D; 5-D; 6-E; 7 - F; 8-G; 9-G; 10- H. Identical strains (PFGE type D and type G) are shown in lanes 4 and 5 and 8 and 9 , respectively (De $G$ ). The remaining lanes represent strains with unique PFGE patterns. $\lambda$ - lambda marker.

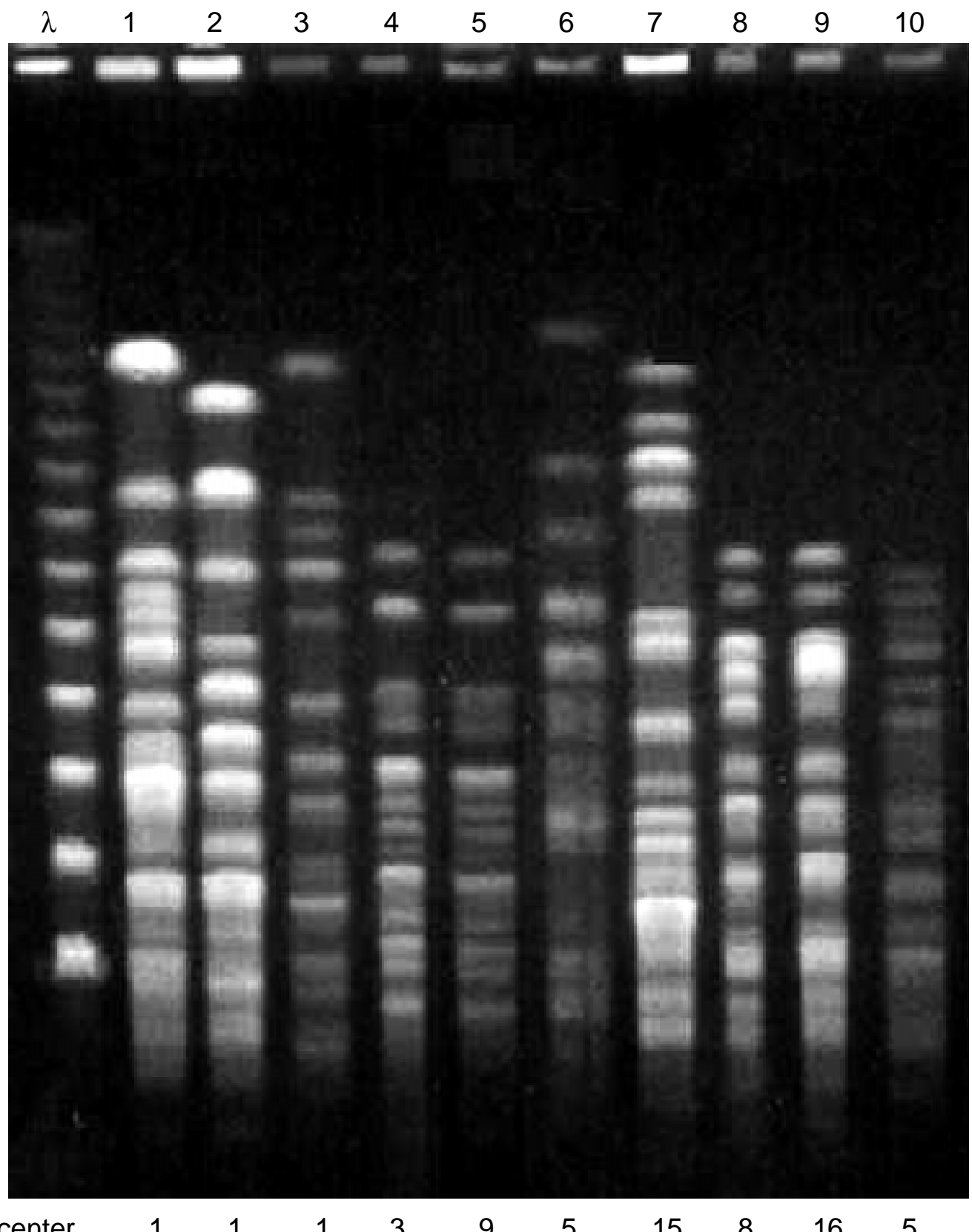

$1 \quad 1 \quad 1 \quad 3$


Figure 4. Pulsed-field gel electrophoresis patterns of Citrobacter spp. (lane-PFGE pattern): 1 - A; 2-B;3$\mathrm{C} ; 4-\mathrm{D}_{1 ;} 5-\mathrm{E} ; 6-\mathrm{F} ; 7-\mathrm{D}_{2 ;} 8-\mathrm{Z}$ (control $\left.\mathrm{S}\right)$. Similar strains (PFGE patterns $\mathrm{D}_{1}$ and $\mathrm{D}_{2}$ ) are shown in lanes 4 and 7 . The remaining lanes represent strains with unique PFGE patterns $\lambda$ - lambda marker.

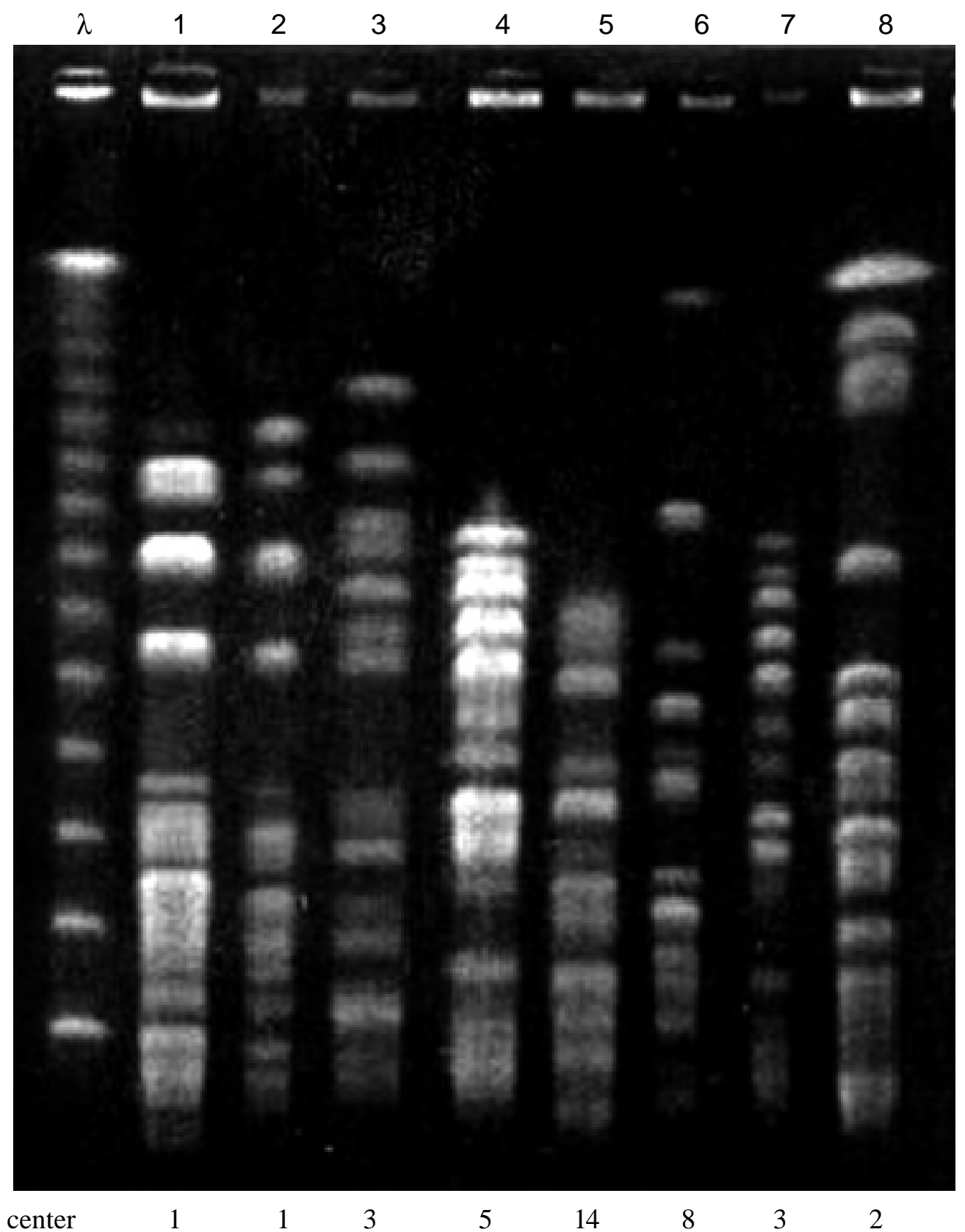


dissemination of specific pathogens, especially MDR bacteria $[10,17]$. In any surveillance program the phenotypic characterization of microorganisms and the identification of clusters of isolates of certain species and of resistance phenotypes is the primary role of the microbiology laboratory. Consequently, the surveillance laboratory serves as an "early warning system," alerting the submitting institution of a potential problem with resistant organisms in the patient population [8]. In most of the existing antimicrobial resistance surveillance programs, whether they are local, regional, national, or international in scope, the process does not go much beyond phenotypic characterization and reporting. However, to be of maximum service to individual hospitals, regions, or countries, the surveillance laboratory must go one step further and provide a rapid assessment of microbial clonality by molecular typing [8]. The Sentinela Program is one of the rare examples of regional surveillance programs that use molecular typing characterization of microorganisms to evaluate the dissemination of resistance mechanisms. We have clearly demonstrated clonal dissemination of MDR strains among Brazilian hospitals.

The rapid emergence and dissemination of drug resistance among bacteria has provoked a call for control of these pathogens as a strategic priority for hospitals on a global scale [18], and the finding of clones within a phenotypically identical cluster may have a direct impact on the method of intervention [19]. If the clustered isolates are genotypically different, then the clustering may be due to chance alone, to grouping together of several highly susceptible patients, or to excessive drug pressure, resulting in the selection of a resistant phenotype within a group of unrelated isolates. Clonal dissemination of a resistant strain illustrates the need for more extensive investigations to identify the mechanism of spread and for renewed attention to infection control efforts.

The identification of an endemic resistance problem that is due to the occurrence of multiple clusters of organisms requires a composite approach involving antimicrobial restrictions and focused use of barrier infection-control precautions [19]. Determination of the resistance genotype provides insight into the mechanism of resistance and it may be necessary in order to understand whether a resistance problem is due to the transmission of resistance genes from organism to organism (controlled by antimicrobial restrictions) or through the transmission of a single resistant strain (controlled by infection-control precautions). Identification of a subpopulation of organisms that are first-step mutants in a multistep pathway leading to high-level resistance (e.g., fluoroquinolone resistance) may trigger strategies that can both prevent the development of high-level resistance and improve therapy overall [20].

On a broader scale, identification of resistant clones with extensive geographic distributions may provide insight into strain virulence and pathogenesis and also may result in public health interventions, such as vaccination and antimicrobial restrictions aimed at reducing the spread of the pathogen and the resistance problem. These considerations provide the rationale for the comprehensive molecular typing program that is an integral part of the SENTRY Antimicrobial Surveillance Program [8]. Each year hundreds of organisms are molecularly characterized, the information is reported to the individual participating centers, and the aggregated data are used to help describe the epidemiology of MDR pathogens [10,11,21,22].

Our results are an overview of molecular typing characterization of organisms obtained during the course of an antimicrobial resistance surveillance program. In order to provide a comprehensive molecular characterization service, the organisms themselves must be readily available. This illustrates the need for a central reference laboratory to serve as a repository of organisms, as well as a standardized source for all microbial characterizations. The ability to utilize molecular typing methods to follow the geographic spread of specific clones provides new information and offers additional opportunities for research that may clarify issues of pathogenesis and epidemiology.

\section{References}

1. Jones R.N., Pfaller M.A. Bacterial resistance: A worldwide problem. Diagn Microbiol Infect Dis 1998;31:379-88. 
2. Tenover F.C. Development and spread of bacterial resistance to antimicrobial agents: An overview. Clin Infect Dis 2001;33(Suppl 3):108S-15S.

3. Sader H.S., Gales A.C., Granacher T.L., et al. Prevalence of antimicrobial resistance among respiratory tract isolates in Latin America: Results from SENTRY Antimicrobial Surveillance Program (1997-98). Braz J Infect Dis 2000; 4:246-55.

4. Sader H.S., Jones R.N., Ballow C.H., et al. Antimicrobial susceptibility of quinupristin/dalfopristin tested against Gram-positive cocci from Latin America: Results from the Global SMART (GSMART) Surveillance Study. Braz J Infect Dis 2001;5:21-30.

5. Spencer R.C., Bauernfeind A., Garcia-Rodriguez J., et al. Surveillance of the current resistant of nosocomial pathogens to antimicrobials. Clin Microbiol Infect 1997;3(Supp 1):21S-35S.

6. Sader H.S., Pignatari A.C., Leme I., et al. Epidemiologic typing of multiply drug resistant Pseudomonas aeruginosa isolated from an outbreak in a intensive care unit. Diagn Microbiol Infect Dis 1993;17:13-8.

7. Sader H.S., Pfaller M.A., Hollis R.J. The use of molecular techniques in the epidemiology and control of hospital infectious. Clin Lab Med 1995; 15:407-31.

8. Pfaller M.A., Acar J., Jones R.N, et al. Integration of molecular characterization of microrganisms in a global antimicrobial resistance surveillance program. Clin Infec Dis 2001;32(suppl2):156S-67S.

9. Cereda R.F., Gales A.C., Jones R.N., Sader H.S. Molecular typing and antimicrobial susceptibility of vancomycinresistant Enterococcus faecium_(VRE) in Brazil. Infect Control Hosp Epidemiol, 2002;3:19-22.

10. Diekema D.J., Pfaller M.A., Turnidge J., et al. Genetic relatedness of multidrug-resistant, methicillin (oxacillin)resistant Staphylococcus aureus bloodstream isolates from SENTRY Antimicrobial Resistance Surveillance Centers worldwide, 1998. SENTRY Participants Group. Microb Drug Resist 2000;6:213-21.

11. Gales A.C, Jones R.N., Pfaller M.A., et al. A two year assessment of the pathogen frequency and antimicrobial resistance patterns among organisms isolated from skin and soft tissue infections in Latin American hospitals: results from the SENTRY Antimicrobial Surveillance Program, 1997-1998. Int J Infects Dis 2000;4:75-84.

12. Sader H.S. Antimicrobial resistance in Brazil: comparison from two multicenter studies. Braz J Infect Dis 2000:4:91-9.

13. National Committee for Clinical Laboratory Standards (NCCLS) - Approved standard M7-A5: Methods for dilution antimicrobial susceptibility test for bacteria that grow aerobically. Fifth edition. Wayne, PA, 2000.
14. National Committee for Clinical Laboratory Standards (NCCLS). Performance standards for antimicrobial susceptibility testing; Twelfth informational supplement. Document M100-S12. Wayne, PA, 2002.

15. Cormican M.G., Marshall S.A., Jones, R.N. Detection of extended-spectrum $\beta$-lactamase (ESBL) producing strains by Etest ESBL screen. J Clin Microbiol 1996;23: 1880-4.

16. Pfaller M.A., Hollis R.J., Sader H.S. Molecular Biology PFGE Analysis of chromossomal restriction fragment. P.10.5.c.1-10.5.c.11. In: Isenberg H.D. (Ed.). Clinical Microbiology Procedures Handbook. ASM Press. Washington, DC, 1992.

17. Gales A.C., Jones R.N., Turnidge J., et al. Characterization of Pseudomonas aeruginosa isolates: Occurrence rates, antimicrobial susceptibility patterns, and molecular typing in the SENTRY Antimicrobial Surveillance Program, 1997-1999. Clin Infect Dis, 2001;32(Suppl 2):146S-55S

18. Goldmann D.A., Haskins W.C. Control of nosocomial antimicrobial-resistant bacteria: a strategic priority for hospitals worldwide. Clin Infect Dis, 1997;24(Suppl 1):139S-45S

19. Hacek D.M., Suriano T., Noskin G.A., et al. Medical and economic benefit of a comprehensive infection control program that includes routine determination of microbial clonality. Am J Clin Pathol, 1999;111:647-54

20. Gales A.C., Gordon K.A., Wilke W.W., et al. Occurrence of single-point gyr A mutations among ciprofloxacinsusceptible Escherichia coli isolates causing urinary tract infections in Latin America. Diagn Microbiol Infect Dis, 2000;36:61-4.

21. Jones R.N., Kugler K.C., Pfaller M.A., Winokur P.L. Characteristics of pathogens causing urinary tract infections in hospitals in North America: results from the SENTRY Antimicrobial Surveillance Program, 1997. Diagn Microbiol Infect Dis, 1999;35:55-63

22. Winokur P.L., Canton R., Casellas J-M., Legakis N. Variations in the prevalence of strains expressing an extended-spectrum beta-lactamase phenotype and characterization of isolates from Europe, the Americas, and the Western Pacific. Clin Infect Dis, 2001;32(Suppl 2):94S-103S. 